\title{
Relationship between bridging and dimensions of sella turcica with classification of craniofacial skeleton
}

\author{
Farhad Sobuti', Sepideh Dadgar ${ }^{1}$, Ali Seifi', Seyed Jaber Musavi, Hoora Hadian² \\ 'Department of Orthodontics, School of Dentistry, Mazandaran University of Medical Sciences, Sari, Iran \\ 2Department of Oral and Maxillofacial Radiology, School of Dentistry, Mazandaran University of Medical Sciences, Sari, Iran \\ ${ }^{3}$ Department of Community Medicine, Faculty of Medicine, Mazandaran University of Medical Sciences, Sari, Iran
}

\section{Abstract}

Purpose: In orthodontics, it is essential to determine the craniofacial skeleton pattern (class I, II, III) for planning treatment. Sella turcica bridging that is seen on lateral cephalometric radiographs is considered as a normal finding. This study aimed to compare sella turcica bridging and its dimensions in patients with various craniofacial patterns.

Material and methods: A total of 105 lateral cephalometric radiographs (53 men and 52 women), aged 14-26 years, were randomly and equally assigned to three groups of class I, II, and III, respectively. The length, diameter, and depth of the sella turcica as well as sella turcica bridging were determined on radiographs. The chi-squared test was used for assessing the relationship between sella turcica bridging and craniofacial skeleton classification. ANOVA was used for assessing the relationship between the dimensions of the sella turcica and craniofacial skeleton classification. The Pearson's correlation coefficient was used for assessing the relationship between age and the dimensions of the sella turcica.

Results: The sella turcica had a normal shape in $64.76 \%$ of patients, whereas $35.33 \%$ of patients had sella turcica bridging. In total, $11.42 \%$ of patients belonged to class I, $34.28 \%$ to class II, and $66.62 \%$ to class III. The diameter of the sella turcica had a significant relationship with age; the diameter of the sella turcica increased with age $(p<0.001)$.

Conclusions: There is a significant relationship between craniofacial skeleton patterns and sella turcica bridging, i.e., the incidence of sella turcica bridging is higher in class III patients. The sella turcica had a greater diameter in older patients.

Key words: cephalometry, radiography, dental, digital, sella turcica.

\section{Introduction}

The sella turcica is a saddle-shaped intracranial depression in the body of the sphenoid, where the pituitary gland is located [1,2]. At the back of the optic foramen, lies the anterior clinoid processes that is medioposteriorly attached to the tentorium cerebelli. The posterior wall of the sella turcica is made of a square-shaped plate of bone called the dorsum sellae. At the superior end of the dorsum sellae, there exist two tubercles known as the posterior clinoid processes [2]. The sella turcica is anteriorly bound by the tuberculum sellae and posteriorly by the dorsum sellae.

The pituitary gland is surrounded by the sella turcica; the two clinoid processes are located in front of the pituitary gland with two more processes in its back. The anterior clinoid processes are made of the margin of the medial and anterior parts of the small sphenoid wings, whereas the posterior processes are made by the end part of the dorsum sellae. One of the widely used landmarks in the skull used for cephalometric tracing is the sella point that is located in

Correspondence address:

Hoora Hadian, Department of Oral and Maxillofacial Radiology, School of Dentistry, Mazandaran University of Medical Sciences, Sari, Iran,

e-mail:h.haadian@yahoo.com

Authors' contribution:

A Study design - B Data collection · C Statistical analysis · D Data interpretation - E Manuscript preparation · F Literature search · G Funds collection 
the center of the sella turcica, which is placed in the middle of the pituitary gland at the base of the skull [3].

Sella bridging is a common morphological variation of the sella turcica. Excessive ossification of the ligaments stretched between the anterior and posterior clinoid processes of the sphenoid along with its abnormal fetal development lead to the development of this abnormal bridge. Therefore, sella bridging can be regarded as a developmental anomaly [4]. Interclinoid ligament ossification of the sella turcica is associated with transformation of the sella turcica, which can be seen in some osseous abnormalities $[5,6]$ and also in some systemic conditions. For example, the incidence of sella turcica malformations is higher in patients with diabetes [7]. The incidence of sella turcica bridging in the general population ranges from 3.6-13\% [5,7-9].

Some studies have illustrated the transformation of the sella turcica during growth [10]. Anatomic anomalies of the sella turcica can be used for interpretation of lateral cephalometric radiographs [2]. Because neural crest cells contribute to the formation and development of the sella turcica, teeth, and all parts of the face, there may be a relationship with the abnormalities of this area [5].

In 2000, Bektor assessed sella turcica bridging in patients with severe craniofacial problems [10]. In 2005, Jones assessed bridging and dimensions of the sella turcica in patients who had been treated with orthodontic surgery or other orthodontic methods [8]. In 2006, Leonardi evaluated sella turcica bridging in patients suffering from dental anomalies [5]. In 2007, Alkofide evaluated the morphology and dimensions of the sella turcica in Saudi patients with class I, II, and III patterns [3]. In 2008, he assessed the shape and dimensions of the sella turcica in patients with dental gap [11]. In 2009, Marsan assessed the incidence of sella turcica bridging and its dimensions in Turkish adult women with malocclusion, and class I and II patterns. The findings revealed that the incidence of bridging was high in class III patients, but sella turcica dimensions were not significantly different between the classes [12]. In 2009, Marcotty, evaluated sella turcica bridging in patients with class I and class III, and reported a higher incidence of sella turcica bridging in class III patients [13]. In 2011, Leonardi measured sella turcica bridging in patients with dental displacement and reported that the incidence of sella turcica bridging was higher in patients with displaced teeth [14]. In 2014, Batool Ali assessed the sella turcica in patients with latent canines and concluded that the incidence of sella turcica bridging was higher in patients with latent canines [15].

Dentists and orthodontists extensively use and evaluate lateral cephalometric radiographs and therefore understanding normal sella turcica variations is important for diagnosing its abnormalities before clinical signs appear $[11,16]$. Currently, numerous researchers, including radiologists and orthodontists, are interested in determining the morphology of the human craniofacial area [17].
One of the recent theories concerns the relationship between the shape and size of the sella turcica and craniofacial classes I, II, III. In orthodontics, the type of craniofacial skeleton is classified into three groups according to the anteroposterior relationship of the maxilla and the mandible (class I, II, III). This can help identify and treat patients seeking orthodontic treatment [18].

This study aimed to assess and compare bridging and dimensions of the sella turcica in patients with classes I, II, and III who presented to an oral and maxillofacial radiology ward, School of Dentistry, Sari.

\section{Material and methods}

We studied 105 cephalometric radiographs (35 cases in each class) of patients aged 14-26 years who presented to the School of Dentistry in Sari for orthodontic treatment between 2015 and 2016. Each group comprised of an equal number of male and female patients. Radiographs that were acceptable for assessment were selected, and the patients were divided into three classes as follows: class I, II, and III based on the anteroposterior skeletal relationship. The samples were randomly selected from among 1190 radiographs of patients in the above-mentioned age range. This age range was selected because no significant changes occur in the shape and size of the sella turcica after puberty (over 14 years of age) [3]. Radiographs were processed by Digital Panoramic Device (Soredex Finland, Helsinki). Radiographs were prepared by a trained and skilled technician under standard conditions using a special instrument and a cephalostat with a fixed magnification. Only radiographs with clearly visible sella turcica were used. The selected radiographs were classified based on the craniofacial skeletal pattern ( 35 cases in each class with an equal distribution of men and women).

Radiographs were divided into three groups based on the ANB angle as follows: class I - ANB angle within the range of $\pm 2^{\circ}$; class II - ANB angle $>4^{\circ}$, and class III - ANB angle $<0^{\circ}$. The craniofacial skeleton pattern was divided into three groups (class I, class II, and class III) based on the maxillary and mandibular anterior-posterior relationship. These three groups are explained in accordance with the ANB angle based on Steiner's analysis. Points A, N, and $B$ can be specified on the lateral cephalometric radiograph. Point A is the most concave point at the frontal maxillary alveolar ridge; point $B$ is the most concave point at the mandibular anterior surface, and point $\mathrm{N}$ is the most anterior point in the frontonasal suture [3].

Wit's analysis was used to overcome the limitations of the ANB angle [19]. The skeletal pattern was determined based on appropriate measurements and confirmed by an orthodontist (Figures 1 and 2).

Acetate paper and black pencil ( $0.5 \mathrm{~mm}$ tip) were used to trace cephalometric radiographs under ideal illumination. Radiographs were traced by a dentistry student and controlled by two orthodontics specialists. 
According to Silverman [20] and Kisling [21], the distance between the dorsum sellae and the tuberculum sellae is measured; (a) indicates the length of sella turcica. The vertical line (c) which is plotted perpendicular to (a) from the deepest point of the sella turcica indicates the depth of sella turcica. The greatest anteroposterior distance of the sella turcica is called the diameter of sella turcica which is plotted from the tuberculum sellae to the farthest point on the inner surface of the posterior wall of sella turcica. All the measurements were done with a ruler. The accuracy of the ruler was $0.001 \mathrm{~m}$. All the reference points and dimensions were checked by an oral and maxillofacial radiologist.

The modified technique of Leonardi was used for determining sella turcica bridging ( 8 and 9 ). In this technique, the length and diameter of sella turcica are measured. If the length is greater than three quarters of the diameter, and there are no calcifications, this is classified as class I. If the length is less than three quarters of the diameter, and there is partial calcification, this means class II. If only one diaphragm of the sella turcica is observed or the distance between the anterior and posterior clinoid processes is less than $1 \mathrm{~mm}$, or there is full calcification, this is class III.

To determine the reliability of measurements, 15 radiographs were re-measured. The correlation between the two measurements was evaluated by the kappa coefficient. Also, SPSS statistical software, version 16 , was used for analyzing the results. Mean variance $( \pm)$ was used to show the range of data, and percentage (\%) was used for the classified variables. ANOVA was used to compare sella turcica dimensions with bridging and craniofacial skeleton calcification. The $\chi^{2}$ test was also used. $P$ value less than 0.05 was considered significant.

\section{Results}

The $\chi^{2}$ test indicted a significant relationship between sella turcica bridging and craniofacial skeleton classification $(p<0.001)$, i.e. sella turcica bridging was more prevalent in patients with craniofacial skeleton class III. Pearson's correlation coefficient showed a statistically significant relationship between age and the diameter of sella turcica $(p<0.001)$; the diameter of the sella turcica increased with age. There was no significant relationship between the length of sella turcica and craniofacial skeleton classification $(p<0.081)$, between the diameter of sella turcica and craniofacial skeleton classification $(p<0.409)$, and between the depth of sella turcica and craniofacial skeleton classification $(p<0.658)$. No significant difference was observed between genders with respect to sella turcica bridging $(p<0.89)$. Also, there was no correlation between age and sella turcica bridging $(p<0.819)$ (Tables 1-7, Figures 3-8).

\section{Discussion}

Sella bridging is a common morphology variation of the sella turcica. Excessive ossification of the ligaments

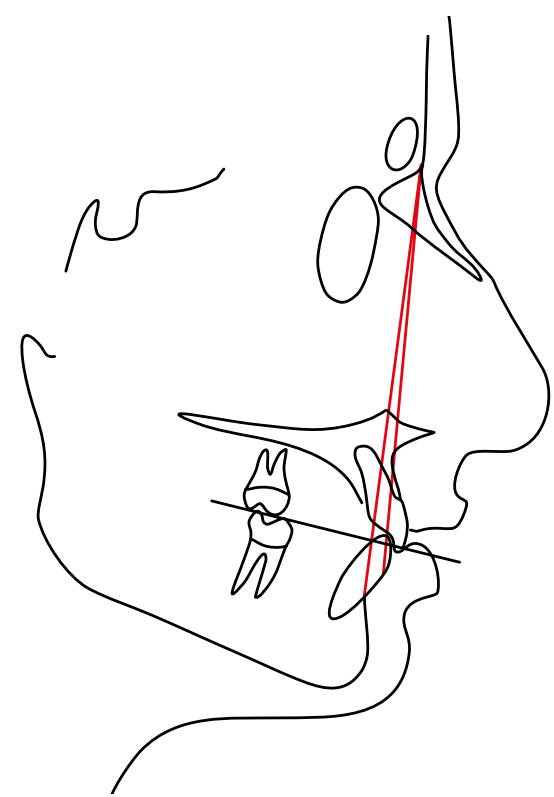

Figure 1. Anteroposterior relationship of the maxilla and mandible based on Steiner's analysis

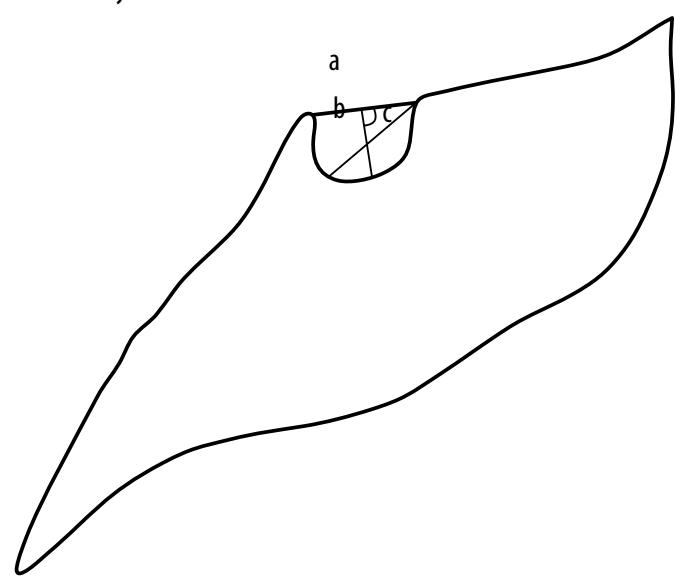

Figure 2. Calculation of sella turcica dimensions using Silverman technique

Table 1. Association between sella bridging and patient characteristics

\begin{tabular}{|l|c|}
\hline Variables & $p$ value \\
\hline Facial skeletal classification and sella bridging & $0.001^{*}$ \\
\hline Sex and sella bridging & 0.89 \\
\hline Age and sella bridging & 0.819 \\
\hline
\end{tabular}

${ }^{*} p<0.05$

between the anterior and posterior clinoid processes of the sphenoid along with abnormal fetal development of the sphenoid lead to the formation of an abnormal bridge. Thus, sella bridging can be regarded as a developmental anomaly.

\section{Prevalence of sella turcica bridging}

The prevalence of sella turcica bridging, as a normal anatomical variation, ranges from $5.5 \%$ to $22 \%$ [6,11]. However, it is reported more often in patients with craniofacial prob- 
Table 2. Association between facial skeletal classification and dimensions of sella turcica

\begin{tabular}{|l|c|}
\hline Variables & $p$ value \\
\hline Length of sella turcica and facial skeletal classification & 0.081 \\
\hline Diameter of sella turcica and facial skeletal classification & 0.409 \\
\hline Width of sella turcica and facial skeletal classification & 0.658 \\
\hline
\end{tabular}

Table 3. Association between age and dimensions of sella turcica

\begin{tabular}{|l|c|}
\hline Variables & $p$ value \\
\hline Length of sella turcica and age & 0.081 \\
\hline Diameter of sella turcica and age & 0.409 \\
\hline Width of sella turcica and age & 0.658 \\
\hline
\end{tabular}

Table 4. Association between sella bridging and facial skeletal classification

\begin{tabular}{|l|c|c|c|}
\hline Bridging & Class I & Class II & Class III \\
\hline Present & 4 & 12 & 21 \\
\hline Absent & 31 & 23 & 14 \\
\hline Total & 35 & 35 & 35 \\
\hline
\end{tabular}

Table 5. Characteristics of sella turcica in patients

\begin{tabular}{|l|c|c|c|c|}
\hline Variables & & Length & Diameter & Width \\
\hline \multirow{4}{*}{ Mean } & Class I & 8.14 & 10.09 & 6.43 \\
\cline { 2 - 5 } & Class II & 9.71 & 10.20 & 6.51 \\
\cline { 2 - 5 } & Class III & 7.23 & 9.80 & 6.66 \\
\hline Std. deviation & Class I & 1.768 & 1.22 & 0.979 \\
\cline { 2 - 5 } & Class II & 1.738 & 1.324 & 1.197 \\
\cline { 2 - 5 } & Class III & 1.750 & 1.302 & 0.068 \\
\hline \multirow{4}{*}{ Min } & Class I & 3 & 7 & 5 \\
\cline { 2 - 5 } & Class II & 5 & 8 & 4 \\
\cline { 2 - 5 } & Class III & 4 & 7 & 4 \\
\hline \multirow{4}{*}{ Max } & Class I & 13 & 12 & 9 \\
\cline { 2 - 5 } & Class II & 11 & 13 & 9 \\
\cline { 2 - 5 } & Class III & 11 & 12 & 8 \\
\hline
\end{tabular}

Table 6. Frequency of sella bridging in patients

\begin{tabular}{|l|c|c|c|}
\hline \multirow{2}{*}{ Age } & Bridging & Count & Mean \\
\cline { 2 - 4 } & Present & 37 & 20.27 \\
\cline { 2 - 4 } & Absent & 68 & 20.08 \\
\hline
\end{tabular}

Table 7. Frequency of sella bridging in patients

\begin{tabular}{|l|c|c|c|}
\hline \multirow{3}{*}{ Sex } & Bridging & Male & Female \\
\cline { 2 - 4 } & Present & 19 & 18 \\
\cline { 2 - 4 } & Absent & 34 & 34 \\
\hline
\end{tabular}

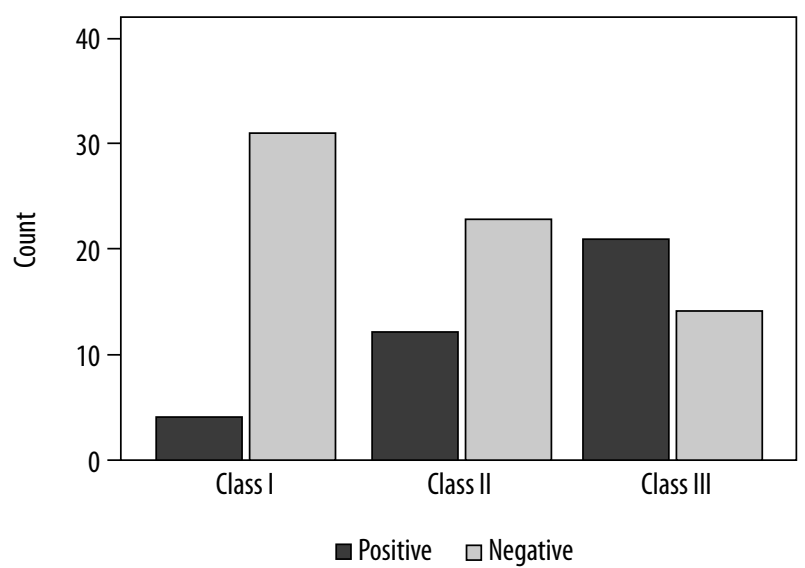

Figure 3. Comparison of sella bridging and facial skeletal classification

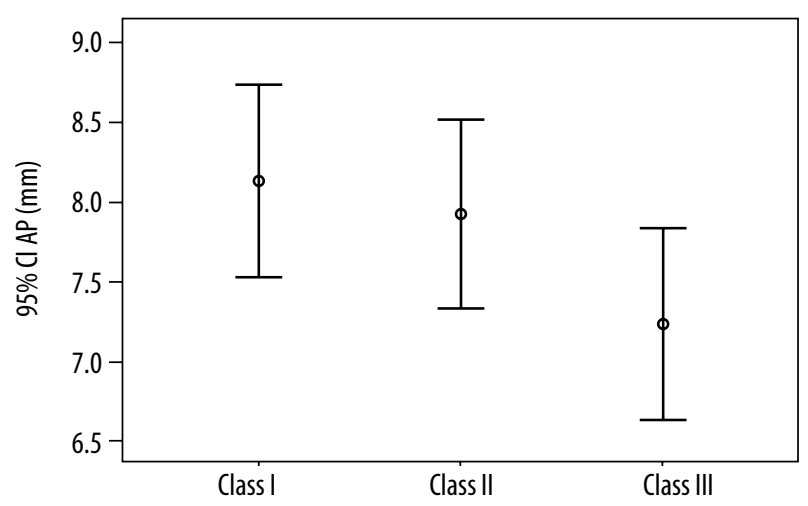

Figure 4. Mean sella turcica lengths in three groups

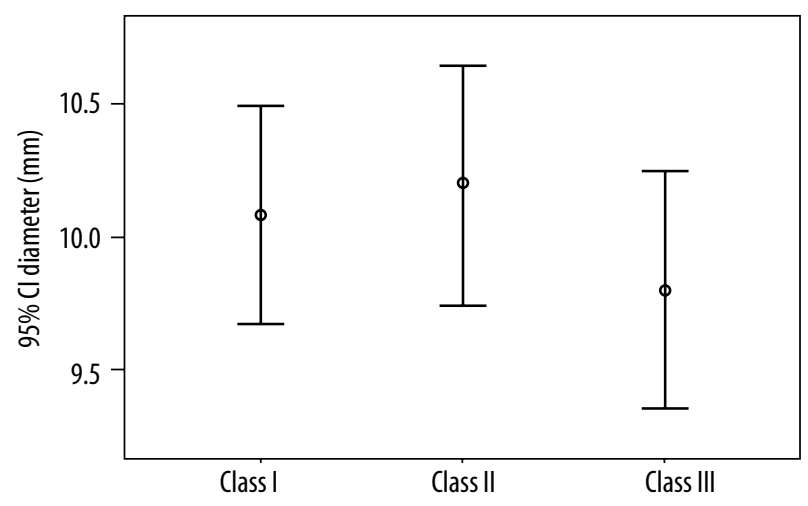

Figure 5. Mean sella turcica diameters in three groups

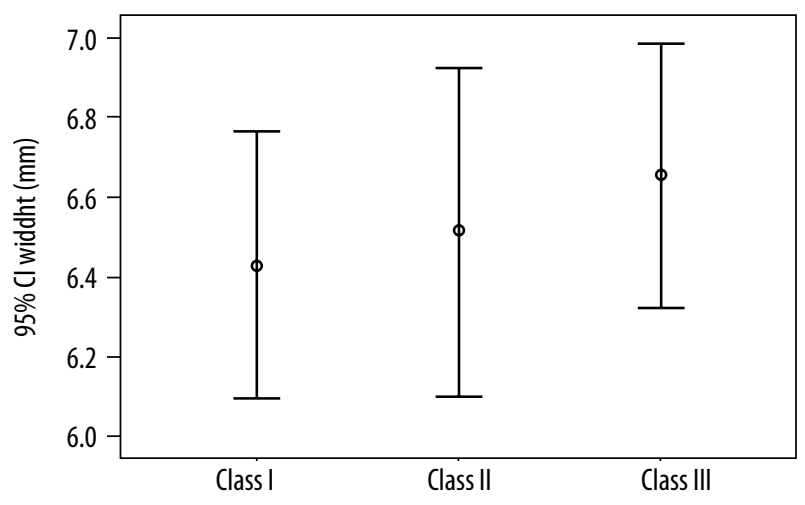

Figure 6. Mean sella turcica widths in three groups 
lems [10]. In this study, sella turcica bridging was observed in $35.23 \%$ of patients. In the study by Moslemzade et al., the prevalence of sella turcica bridging was $8.3 \%$ [18]. In the study by Alkofide, $1.1 \%$ of patients had sella turcica bridging [3]. In the study by Bektor et al., the prevalence of sella turcica bridging in patients with extreme craniofacial problems was $18.6 \%$ [10]. In the study by Axelsson et al., performed in patients with Williams syndrome, the prevalence of sella turcica bridging was 13\% [9]. Kader reported that the prevalence of sella turcica bridging was 3.74\% among patients who underwent orthodontic treatment [22].

\section{Sella turcica bridging - age and gender}

In our study, no significant difference was found between men and women with respect to the length, diameter, and depth of sella turcica, which is in line with the studies by Alkofide [3] and Shah [23].

\section{Dimensions of sella turcica - age}

Age was significantly associated with the diameter of sella turcica, i.e., the diameter of sella turcica increased with age. However, no relationship was found between age and the length and depth of sella turcica. In a study by Alkofide, the size of sella turcica was greater in older patients [3]. Also, Preston found a close relationship between the size of the pituitary fossa and age [24]. Choi et al. reported a significant relationship between linear dimensions of sella turcica and age, up to 25 years of age [17] but not in older patients [3].

\section{Dimensions of sella turcica - craniofacial skeleton pattern}

Few studies have investigated the correlation between craniofacial skeleton pattern and the size of sella turcica. In the present study, the length, diameter, and depth of sella turcica were the same in all three craniofacial skeleton groups. Likewise, Preston did not find a significant relationship between craniofacial skeleton pattern and the size of pituitary fossa $[23,24]$. Unlike our study, Valizade et al. reported that the length of sella turcica in class III patients was higher than in those in class I and II, while the diameter and depth of sella turcica were the same in all three groups [25]. However, Alkofidde reported a significant relationship between class II or III skeletal patterns and the diameter of sella turcica [3]. Moslemzade et al. reported a significant difference between class I and class III patients with respect to the length of sella turcica [18].

\section{Sella turcica bridging - age and gender}

The present study revealed no significant relationship between sella turcica bridging and age or gender. Likewise, Alkofide found no significant relationship between these variables [3].

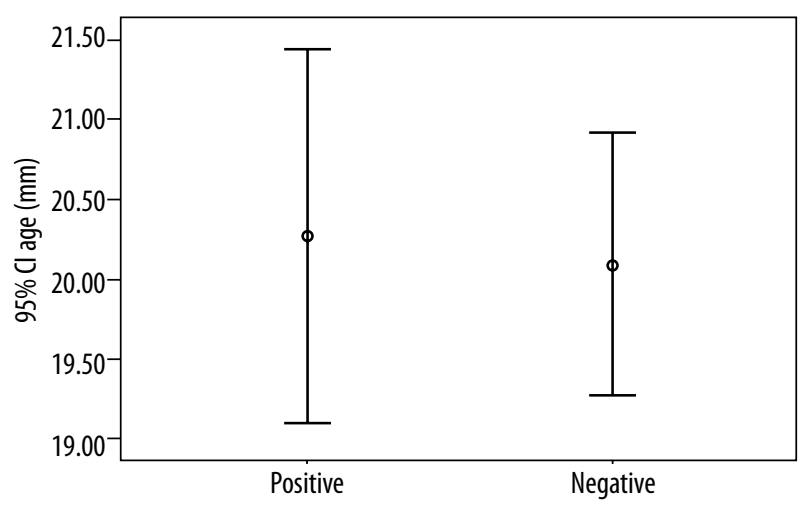

Figure 7. Comparison of sella bridging and age

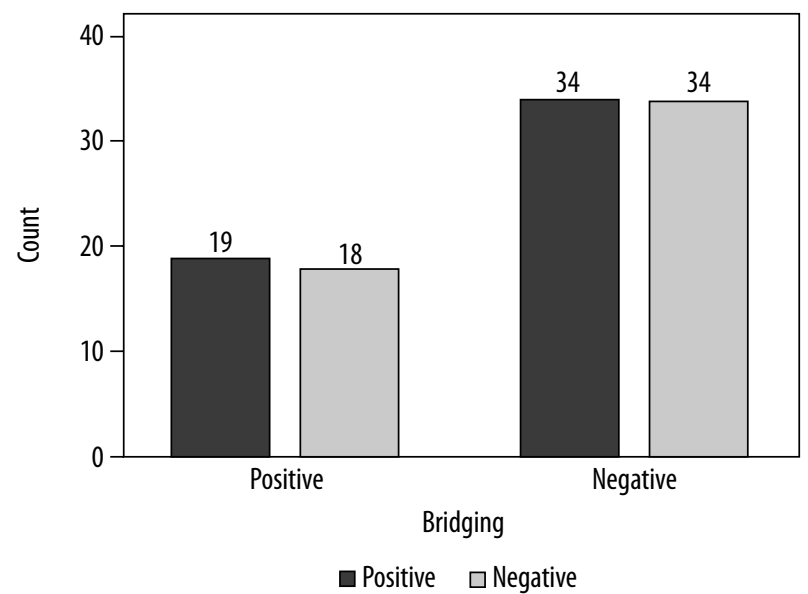

Figure 8. Comparison of sella bridging and sex

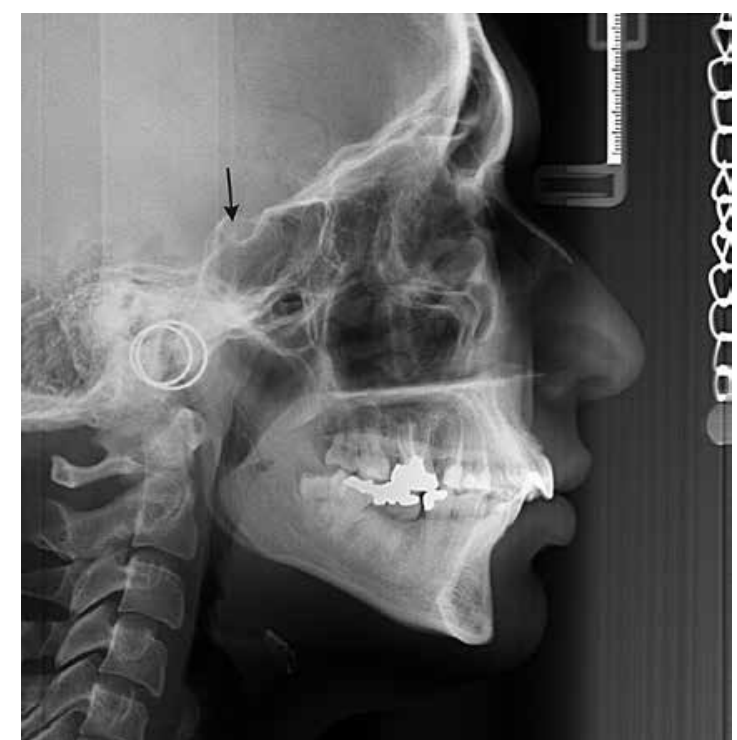

Figure 9. An example of sella turcica bridging on a lateral cephalometry image

\section{Sella turcica bridging - craniofacial skeleton pattern}

Our study revealed that the prevalence of sella turcica bridging in patients with craniofacial skeleton class III (60.00\%) was more prevalent than in class II (34.58\%) and class I (11.42\%) patients. Valizade reported the prev- 
alence of sella turcica bridging of $13.8 \%$ in class I, $12.9 \%$ in class II, and $43.3 \%$ in class III [25]. Mayer-Marcotty et al. reported the prevalence of sella turcica bridging of $9.4 \%$ in class I and $16.8 \%$ in class III patients [13]. The prevalence of sella turcica was found to be greater in our study than in the studies by Cederberg et al. [2], Jones et al. [8], and Leonardi et al. [5]. Based on anatomic studies, in which female skulls without anomalies were analyzed using lateral cephalometric radiographs, the prevalence of sella turcica bridging is between $1.75 \%$ and $6 \%$ [26-28]. The differences between anatomic studies and those that used lateral cephalometric radiographs is due to the superimposition of the sella turcica clinoid processes [13]. The prevalence of sella turcica bridging in this study differs from that reported in the studies by Valizade et al. and Hussein Moslemzade. This difference may be due to different ethnicities of the studied groups.

\section{Conclusions}

In conclusion, there is a significant relationship between age and the diameter of sella turcica in post-puberty patients, i.e., the diameter of sella turcica rises with age. There is no relationship between age and the length and depth of sella turcica. There is a strong relationship between various craniofacial skeleton patterns and sella turcica bridging, such that the prevalence of sella turcica bridging (Figure 9) is higher in class III than in class I and class II patients.

\section{Conflict of interest}

The authors report no conflict of interest.

\section{References}

1. Hasan HA, Alam MK, Yusof A et al: Size and morphology of sella turcica in Malay populations: A 3D CT study. J Hard Tissue Biol 2016; 25: 313-320.

2. Cederberg R, Benson B, Nunn M, English J. Calcification of the interclinoid and petroclinoid ligaments of sella turcica: A radiographic study of the prevalence. Orthod Craniofac Res 2003; 6: 227-232.

3. Alkofide EA. The shape and size of the sella turcica in skeletal Class I, Class II, and Class III Saudi subjects. Eur J Orthod 2007; 29: 457-463.

4. Skrzat J, Szewczyk R, Walocha J. The ossified interclinoid ligament. Folia Morphol (Warsz) 2006; 65: 242-245.

5. Leonardi R, Barbato E, Vichi M, Caltabiano M. A sella turcica bridge in subjects with dental anomalies. Eur J Orthod 2006; 28: 580-585.

6. Kantor ML, Norton LA. Normal radiographic anatomy and common anomalies seen in cephalometric films. Am J Orthod Dentofacial Orthop 1987; 91: 414-426.

7. Bavbek NC, Dincer M. Dimensions and morphologic variations of sella turcica in type 1 diabetic patients. Am J Orthod Dentofacial Orthop 2014; 145: 179-187.

8. Jones R, Faqir A, Millett D, et al. Bridging and dimensions of sella turcica in subjects treated by surgical-orthodontic means or orthodontics only. Angle Orthod 2005; 75: 714-718.

9. Axelsson S, Storhaug K, Kjær I. Post-natal size and morphology of the sella turcica. Longitudinal cephalometric standards for Norwegians between 6 and 21 years of age. Eur J Orthod 2004; 26: 597-604.

10. Becktor JP, Einersen S, Kjær I. A sella turcica bridge in subjects with severe craniofacial deviations. Eur J Orthod 2000; 22: 69-74.

11. Alkofide EA. Sella turcica morphology and dimensions in cleft subjects. Cleft Palate Craniofac J 2008; 45: 647-653.

12. Marşan G, Öztaş E. Incidence of bridging and dimensions of sella turcica in Class I and III Turkish adult female patients. World J Orthod 2009; 10: 99-103.

13. Meyer-Marcotty P, Reuther T, Stellzig-Eisenhauer A. Bridging of the sella turcica in skeletal Class III subjects. Eur J Orthod 2010; 32: 148-153.
14. Leonardi R, Farella M, Cobourne MT. An association between sella turcica bridging and dental transposition. Eur J Orthod 2011;33: 461-465.

15. Ali B, Shaikh A, Fida M. Association between sella turcica bridging and palatal canine impaction. Am J Orthod Dentofacial Orthop 2014; 146: 437-441.

16. Kjær I, Hjalgrim H, Russell BG. Cranial and hand skeleton in fragile X syndrome. Am J Med Genet 2001; 100: 156-161.

17. Choi WJ, Hwang EH, Lee SR. The study of shape and size of normal sella turcica in cephalometric radiographs. Korean Journal of Oral and Maxillofacial Radiology 2001; 31: 43-49.

18. Moslemzadeh SH, Moghaddam N, Foroughi Moghaddam S, et al. Relationship Between bridging and dimensions of sella turcica and antro-posterior skeletal malocclusions in children. Iran J Orthodont 2016; 11: e5738.

19. Proffit W, Sarver D, Ackerman J. Orthodontic diagnosis: The problem-oriented approach. Contemporary Orthodontics. $5^{\text {th }}$ ed. Mosby, St. Louis 2013; 150-219.

20. Silverman FN. Roentgen standards fo-size of the pituitary fossa from infancy through adolescence. Am J Roentgenol Radium Ther Nucl Med 1957; 78: 451-460.

21. Kisling E. Cranial morphology in Down's syndrome: A comparative roentgenencephalometric study in adult males. Munksgaard, Copenhagen 1966.

22. Abdel-Kader HM. Sella turcica bridges in orthodontic and orthognathic surgery patients. A retrospective cephalometric study. Aust Orthod J 2007; 23: 30-35.

23. Shah AM, Bashir U, Ilyas T. The shape and size of the sella turcica in skeletal Class I, II and III in patients presenting at Islamic International Dental Hospital, Islamabad. Pakistan Oral Dent J 2011; 31 : 104-110.

24. Preston CB. Pituitary fossa size and facial type. Am J Orthod 1979; 75: 259-263. 
25. Valizadeh S, Shahbeig S, Mohseni S, et al. Correlation of shape and size of sella turcica with the type of facial skeletal class in an Iranian group. Iran J Radiol 2015; 12: e16059.

26. Busch W. Die Morphologie der Sella turcica und ihre Beziehungen zur Hypophyse. Virchows Archiv 1951; 320: 437-458 [in German].
27. Müller F. Die bedeutung der sellabrücke für das auge. Klinische Monatsblätter für Augenheilkunde 1952; 120: 298-302 [in German].

28. Platzer W (ed.). Zur Anatomie der "Sellabrücke" und ihrer Beziehung zur A. carotis interna. RöFo-Fortschritte auf dem Gebiet der Röntgenstrahlen und der bildgebenden Verfahren. Georg Thieme Verlag KG Stuttgart, New York 1957 [in German]. 